\title{
Дополнитемьное образование
}

\section{УДК 378}

\section{Социальная ответственность сотрудника ОВД: сущность и диагностика}

\section{Social responsibility of a police officer: essence and diagnostics}

Никулин С.Г., Казанский юридический институт МВД России, ФГБНУ «Институт педагогики, психологии и сочиальных проблем», kazanreds@gтаil.com

Nikulin S., Kazan Law Institute of the Ministry of Internal Affairs of Russia, FSBNU "Institute of

Pedagogy, Psychology and Social Problems", kazanreds@gmail.com

DOI: $10.51379 / \mathrm{KPJ} .2021 .148 .4 .024$

Ключевые слова: дополнительное профессиональное образование, сотрудник ОВД, социиальная ответственность, дисциплинарная ответственность, диагностика.

Keywords: additional professional education, police officer, social responsibility, disciplinary responsibility, diagnostics.

Аннотация. Актуальность статьи обусловлена тем, что социальная ответственность сотрудника ОВД не всегда регламентируется какими-либо установками или инструкииями, между тем, ее ключевая функиия находит выражение в побуждении к сочиально ориентированной, полезной деятельности с высоким уровнем самоотдачи, то есть той деятельности, которую на профессиональной основе осуществляют сотрудники ОВД. В статье приведено авторское видение сочиальной ответственности сотрудника ОВД, раскрывающей свое содержание через когнитивный, этический, поведенческий, коммуникативный и рефлексивный компоненты. В ичелях апробации диагностического инструментария приведень результаты констатирующего эксперимента по состоянию социальной ответственности у сотрудников ОВД, с различным опытом работы в системе и курсантов вуза МВД России (младиих и старших курсов). Проверена валидность методик исследования и показаны принципиальные различия в представлениях дисииплинарной и социальной ответственности. Полученные выводы предполагают необходимость усиления воспитательной работы в системе высшего и дополнительного образования вузов МВД России.

Abstract. The relevance of the article is due to the fact that the social responsibility of a police officer is not always regulated by any guidelines or instructions, meanwhile, its key function is expressed in the incentive to socially oriented, useful activity with a high level of dedication, that is, the activity that on a professional basis carried out by police officers. The article presents the author's vision of the social responsibility of a police officer, revealing its content through cognitive, ethical, behavioral, communicative and reflective components. In order to test the diagnostic tools, the results of the ascertaining experiment on the state of social responsibility among police officers with different experience in the system and cadets of the Ministry of Internal Affairs of Russia (junior and senior courses) are presented. The validity of the research methods was checked and the fundamental differences in the views of disciplinary and social responsibility were shown. The findings suggest the need to strengthen educational work in the system of higher and additional education of higher education institutions of the Ministry of Internal Affairs of Russia.

Введение. Тенденция непрерывного образования и профессиональной подготовки повлияла на характер работы всех учреждений дополнительного профессионального образования, включая факультеты ДПО вузов МВД, где проходят обучение начинающие и действующие сотрудники ОВД. Профессиональная подготовка сотрудников ОВД направлена, главным образом, на формирование у них прикладных навыков, профессионально важных качеств и новых свойств личности, необходимых для эффективной профессиональной деятельности. Ранее в авторских исследованиях показано, что среди всего круга профессионально важных качеств и свойств личности сотрудников ОВД, наиболее универсальным для них и значимым, обусловливающим успешность их профессиональной деятельности, выступает социальная ответственность [9;10]. Социальная 
ответственность в психолого-педагогической и юридической литературе рассматривается не только как инструментальное свойство личности и регулятор ее жизнедеятельности, ее ценностей и выборов, но и как показатель ее социальной и психологической зрелости, обеспечивая становление субъекта ответственного поведения [11].

Опираясь на исследование Беспаловой Т.М., подчеркнем, что наиболее ярко социальная ответственность проявляется в экстремальных условиях деятельности, к которым, безусловно, относится служба в ОВД, требующая подлинной ответственности как самодетерминации [2].

Социальная ответственность сотрудника ОВД и ее проявления не всегда регламентируются какими-либо установками или инструкциями. Практика показывает, что социальная ответственность рациональна по своему происхождению и определяется условиями, в которых находится человек. Социальная ответственность проявляется в таких условиях, когда человек вовлечен в осуществление каких-либо изменений и при этом способен демонстрировать свою жизненную позицию. Именно активность в проявлении жизненной позиции определяет характер социальной ответственности человека [14]. Поэтому и ключевая функция социальной ответственности личности находит выражение в побуждении к социально ориентированной, полезной деятельности с высоким уровнем самоотдачи.

Цель статьи: раскрыть содержание социальной ответственности сотрудника ОВД и определить диагностический инструментарий для ее диагностики.

Материаль и методы исследования. Анализ отечественной и зарубежной литературы по проблеме социальной ответственности позволяет выделить два основных подхода к ее изучению, а именно: изучение отдельных аспектов ответственности, либо изучение ее как системного качества личности. Анализируя подходы к исследованию отдельных сторон ответственности отметим, что она была изучена Х. Айзенком, А. Бандурой, Э. Эриксоном как нравственная категория, К.А. АльбухановойСлавской, А.В. Брушлинским, К. Роджерсом с позиции соотношения свободы и ответственности, Г.М. Андреевой, К. Муздыбаевым, Ф. Хайдером - $~ с$ позиции каузальной атрибуции [13]. Широко также известны теории Ж. Пиаже о становлении моральной ответственности и Л. Колберга о стадиях морального развития личности, согласно которым, по мере взросления социальная ответственность имеет несколько векторов развития: от коллективной до индивидуальной, поскольку с развитием общества за поступок отдельного человеку несет не группа, членом которой он является, а сам человек; от внешней ответственности к осознанной, связанной с самоконтролем, к внутренней; от ретроспективного плана ответственности к перспективному, когда личность предвосхищает возможные результаты своих действий и осознает влияние прежних отношений на их настоящие [5].

К. Муздыбаевым ответственность рассматривалась как качество, объясняющее ее социальную типичность. Социальная ответственность, согласно взглядам данного автора, выражает склонность личности придерживаться в своем поведении принятых в конкретном обществе норм, исполнять ролевые обязанности, а также готовность нести ответственность за свои действия [9]. Опора на полученные теоретические постулаты предопределила авторскую трактовку понятия «социальная ответственность сотрудника ОВД».

Апробация

диагностического инструментария по исследованию социальной ответственности проводилась в 2019-2020 году на базе Казанского юридического института МВД. Выборку составили 180 человек, из них были выделены 2 группы: экспериментальная группа - 90 человек, из числа сотрудников ОВД, проходящих обучение по программам ДПО (группа А), и контрольная группа - 90 человек курсантов 1 и 4 курсов КЮИ (группа Б). Согласно логике исследования, в экспериментальной группе были выделены 2 подгруппы: сотрудники ОВД без опыта работа подгруппа A1 (45 человек), сотрудники с опытом работы в системе МВД более 5 лет подгруппа A2 (45 человек). В качестве контрольных групп были выделены курсанты КЮИ: подгруппа Б1 - обучающиеся 1 курса (45 человек), обучающиеся 4 курса - подгруппа Б 2 (45 человек).

Диагностика видов и структурных компонентов социальной ответственности у курсантов и сотрудников ОВД была произведена с помощью стандартизованных психодиагностических методик: «Ответственный ли Вы человек?» А. Махнача, «Шкала социальной ответственности» Л. Берковица и К. Луттермана (по К. Муздыбаеву), опросник «Дисциплинированность» (Д-К) (В.П. Прядеин, Н.В. Воротникова). 
Pезультатьл. Опираясь на исследования социальной ответственности, представленные в работах В.П. Прядеина [12], подчеркнем, что она, как интегральная характеристика личности, связана с реализацией задуманного поведения субъекта в ситуации деятельности и представляет из себя совокупность установок и готовности к реализации задуманного [1]. Определяя ответственность как личностный механизм реализации необходимости, Л.И. Божович, В.С. Герасимова, К.А. АбульхановаСлавская, Г.Г. Горелова, М.В. Осорина, отмечают присвоение личностью внешней необходимости и превращении её во внутреннюю [1].

Социальная ответственность начинает формироваться в юношеском возрасте, интенсивно развиваясь в период интенсивного становления самосознания личности, в тот период, когда начинает формироваться отношение к себе как к субъекту профессиональной деятельности [6]. Однако именно во время профессионального обучения кристаллизуется структура профессиональноважных качеств сотрудников, важнейшим из которых является ответственность [8].

Так, И.В. Зубов описывал следующие особенности становления социальной ответственности, обусловленные спецификой образовательной среды учебного заведения МВД России: правовая доминанта в организации учебно-воспитательного процесса, всей системы служебной деятельности, что формирует законопослушность, легитимность действий и поступков сотрудников ОВД; приоритетность субъект-объектных субординационных отношений, жесткая регламентация учебновоспитательного процесса и всего уклада жизни; усложнение содержания и интенсификация профессиональной деятельности сотрудника ОВД в современных условиях, характеризующихся экстремальным темпом и ритмом, опасностью, риском для жизни [3]. Принимая во внимание важность специфики образовательной среды, указанные И.В. Зубовым, отметим, что в данных условиях, скорее всего формируется дисциплинарная ответственность, чем ответственность социальная.

О.Г. Яковлева, анализируя процесс профессиональной подготовки сотрудников ОВД, отмечает, что социальная ответственность у сотрудников ОВД России формируется в процессе информирования обучающихся о социальной действительности, межличностных отношениях, правах и обязанностях, нормах и правилах социального поведения, санкциях при их нарушениях, традициях профессиональной деятельности сотрудников ОВД, а также рефлексию профессиональной деятельности [16].

Служба в полиции наделяет своих сотрудников властными полномочиями, включая право на применение в случае необходимости физической силы, специальных средств и огнестрельного оружия. Вместе с тем, сотрудники ОВД должны также защищать права и законные интересы граждан. Таким образом, сотрудники ОВД осуществляют свою деятельность в сфере охраны права, обеспечивая безопасность не только общества, но и самих сотрудников [15]. Двойственность функции (защита и принуждение), порождает множество нравственных проблем, связанных с выбором, как между нравственным и безнравственным поведением, так и между разными видами нравственного поведения; соблюдением требований общечеловеческих норм морали и выполнением служебного долга; своими убеждениями, моральными нормами поведения и требованиями закона.

Именно от соблюдения сотрудниками нравственно-этических основ служебной деятельности во многом зависит эффективность выполнения профессиональной деятельности, а социальная ответственность сотрудников ОВД является тем самым фундаментом, от которого зависит соблюдение ими служебной дисциплины и законности [7]. Как отмечает С.А. Гаврилушкин, ответственность является одним из наиболее значимых качеств личности (ядро профессионально важных качеств), от которых зависит эффективность профессиональной деятельности [4].

Опираясь на подход А.П. Прядеина к структуре социальной ответственности отметим, что она включает две сферы: природно заданную (операционную) и прижизненно приобретенную (содержательную). Обе сферы образованы тремя биполярными параметрами: (у каждого есть два противоположных полюса). Так, параметрами операционной сферы выступают эмоциональный, динамический, регуляторный. Параметрами содержательной сферы являются: когнитивный, мотивационный и результативный. Сопоставив функции и структурные компоненты социальной ответственности сотрудника ОВД нами была определена ее структура. 
Таблица 1. - Соответствие функций и содержания соииальной ответственности сотрудников ОВД

\begin{tabular}{|c|c|}
\hline $\begin{array}{c}\text { Функции социальной } \\
\text { ответственности сотрудника ОВД }\end{array}$ & Компонент социальной ответственности сотрудника ОВД \\
\hline Нормативно-правовая функция & $\begin{array}{l}\text { Когнитивный компонент - } \text { формирование образа (образца) } \\
\text { профессионального поведения через знание зафиксированных норм } \\
\text { деятельности и опыта их практических проявлений }\end{array}$ \\
\hline $\begin{array}{l}\text { Ценностно-ориентациионная } \\
\text { функичия }\end{array}$ & $\begin{array}{l}\text { Этический компонент - осознанная готовность следования } \\
\text { профессиональному долгу в противоречивых условиях выбора траектории } \\
\text { профессиональных действий даже в условиях противоречия собственным } \\
\text { стремлениям }\end{array}$ \\
\hline Функиия устойчивости & $\begin{array}{l}\text { Поведенческий компонент }- \text { формирование } \quad \text { собственного } \\
\text { профессионального кодекса поведения, базирующегося на нравственных } \\
\text { нормах профессии }\end{array}$ \\
\hline Функиия взаимодействия & $\begin{array}{l}\text { Коммуникативныц компонент - выстраивание профессиональных } \\
\text { способов профессиональных коммуникаций, связанных с разрешением } \\
\text { социальных задач во взаимодействии с различными категориями граждан }\end{array}$ \\
\hline Оиеноччная функциия & $\begin{array}{l}\text { Рефлексивный компонент - осуществление самоконтроля и самооценки } \\
\text { для прогнозирования последствий выбора траектории собственных } \\
\text { профессиональных действий }\end{array}$ \\
\hline
\end{tabular}

В рамках обоснования выбора комплекса психодиагностического инструментария для диагностики социальной ответственности сотрудников ОВД в соответствии с выделенной структурой автором определено, что сотрудники ОВД, проходящие профессиональное обучение в учебном центре, отличаются разным уровнем социальной ответственности. Так, в ходе констатирующего этапа эксперимента экспериментальная группа (группа А) была разделена на 2 подгруппы в соответствии со стажем работы сотрудников в ОВД. Среди сотрудников ОВД со стажем более 5 лет (группа A1), подавляющее большинство опрошенных респондентов показали средний уровень социальной ответственности, $30 \%$ опрошенных низкий уровень. Как видно из рисунка 1 , всего $10 \%$ опрошенных респондентов из числа сотрудников со стажем работы в ОВД более 5 лет продемонстрировали высокий уровень социальной ответственности.

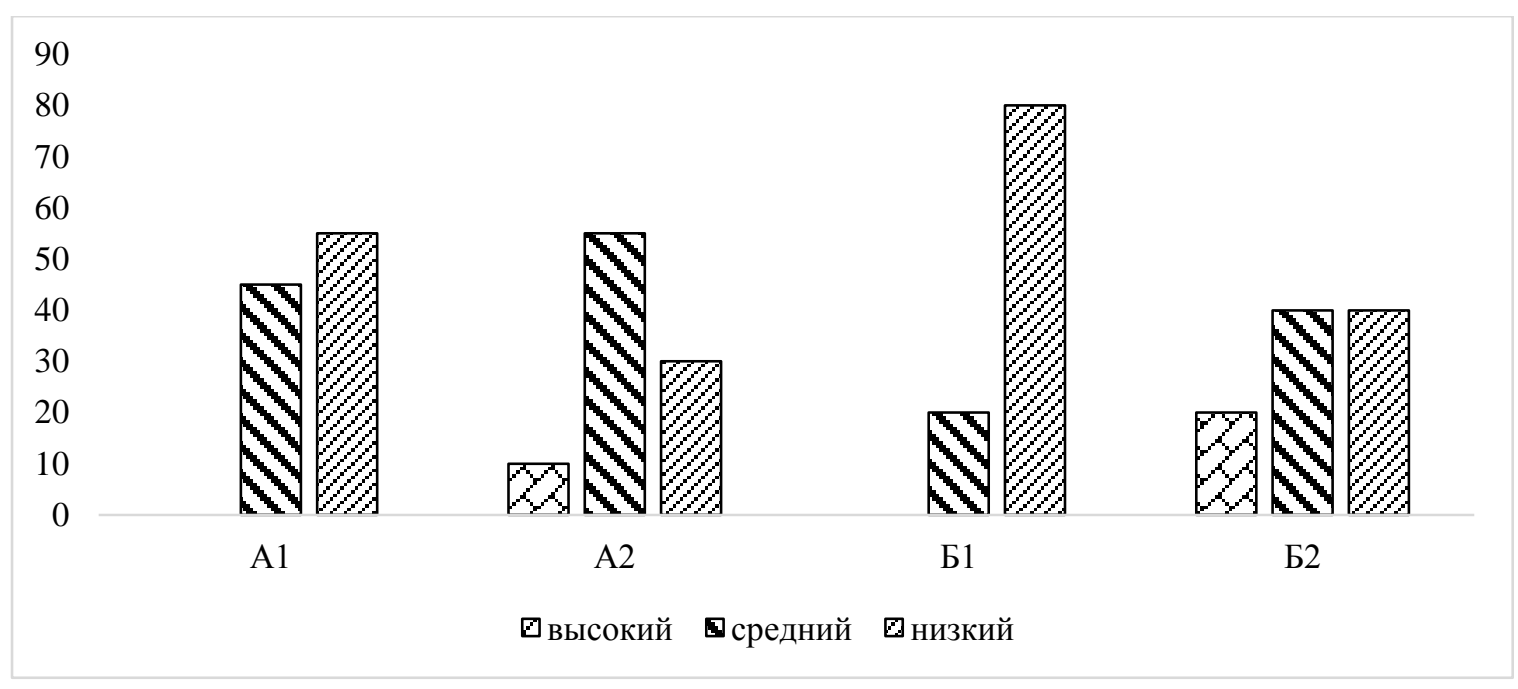

Рисунок 1. - Показатели социальной ответственности, полученные в ходе проведения методики «Ответственный ли Вычеловек?» А. Махнача, в экспериментальной и контрольной группах

Результаты, полученные в ходе проведения методики «Ответственный ли Вы человек?» А. Махнача, свидетельствуют о том, что среди сотрудников ОВД, вновь принятых на работу и имеющих стаж работы в системе МВД менее 3-х лет (группа А2), 45\% опрошенных респондентов показали средний уровень социальной ответственности, остальные в данной группе низкий.

Проведенное исследование в контрольной 
группе (группа Б), состоящей из курсантов младших и старших курсов КЮИ, показало, что 80\% опрошенных респондентов первого кура отличаются низким уровнем социальной ответственности, и только $20 \%$ опрошенных группы Б1 - показали средний уровень сформированности социальной ответственности. В группе курсантов из числа выпускников (Б2) результаты по данной методики распределились следующим образом: по 40\% - средний и низкий уровень социальной ответственности, 20\% опрошенных респондентов из числа выпускников показали высокий уровень социальной ответственности. Полученные результаты говорят о том, что $10 \%$ сотрудников ОВД со стажем работы более 5 лет (группа А2) и 20\% курсантов выпускных курсов (группа Б2) отличаются высоко развитым чувством долга, предпочитают доводить начатые дела до конца, принимают на себя ответственность за других людей, способны жертвовать собой в интересах других. Такие респонденты для достижения своих целей проявляют настойчивость, целеустремленность и упорство, сверхобязательность и точность.

Из рисунка 1 видно, что подавляющее число респондентов групп A1 и А2 показали средний уровень социальной ответственности (45\% и 55\% соответственно). Менее выраженными результатами на среднем уровне социальной ответственности представлены курсанты первого $(20 \%)$ и выпускного (40\%) курсов. Полученные результаты говорят о том, что они обладают чувством ответственности и долга, однако проявляют излишнюю пассивность, избегают принятия полной ответственности за происходящее.

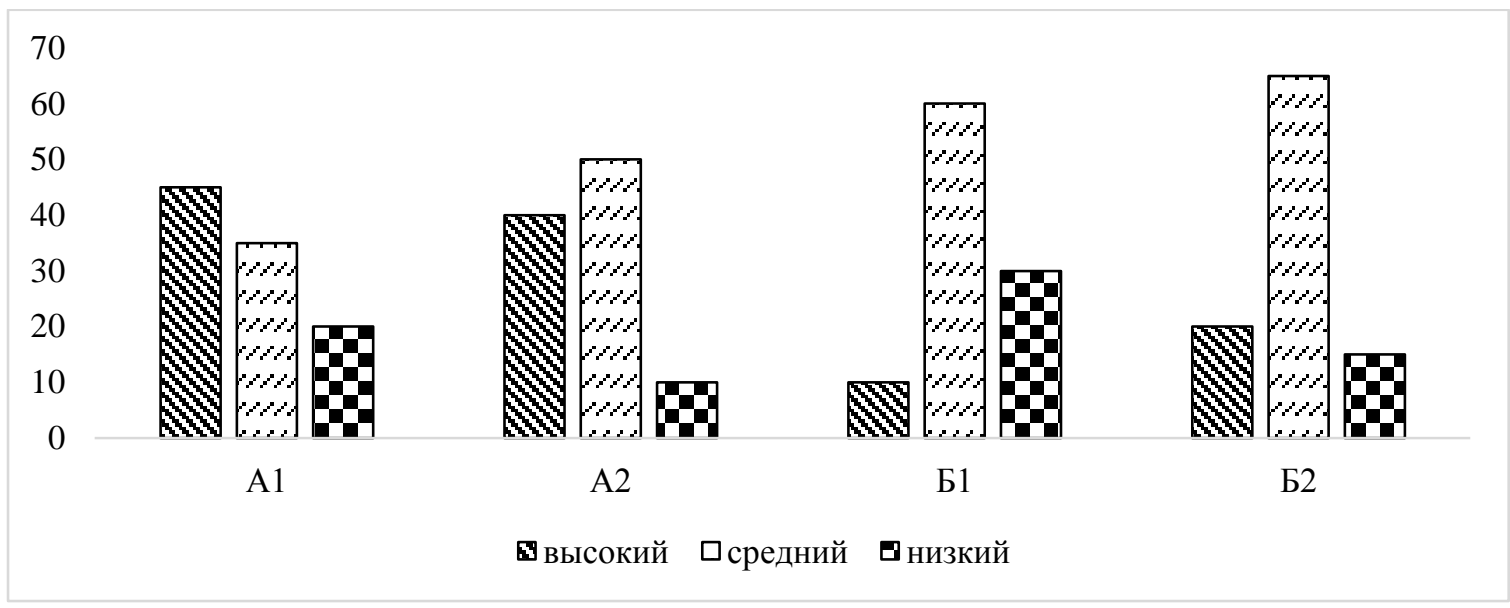

Рисунок 2. - Результаты, полученные в ходе проведения методики «Шкала социиальной ответственности» Л. Берковица и К. Луттермана (по К. Муздьбаеву), в экспериментальных и контрольных группах

Следует подчеркнуть, что достаточное количество респондентов, особенно в группах A1 и Б1, отличаются низким уровнем социальной ответственности. Полученные результаты позволяют сделать вывод о том, что и сотрудники ОВД, и курсанты часто проявляют склонность к спонтанным, а иногда и непоследовательным решениям, допускают неточность и необязательность, легковесно относятся к своим обязанностям.

В ходе проведения методики изучения социальной ответственности Л. Берковица и К. Луттермана (по К. Муздыбаеву [8]), респонденты и контрольной и экспериментальной группы продемонстрировали преимущественно высокие и средние показатели социальной ответственности, что позволяет говорить о наличии у них таких качеств как точность, пунктуальность, исполнительность, честность, готовность отвечать за свои поступки, см. рисунок 2. В этом случае мы можем наблюдать и способность к сопереживанию, чуткость, наличие волевых качеств, усердия, стойкости, выдержки, смелости. Высокие значения по данной методике также подразумевают идейную определенность, общественную сущность, степень включенности личности в систему общественных отношений, склонность личности придерживаться в своем поведении общепринятых социальных норма, исполнения ролевых обязанностей и способность личности дать ответ за свои действия.

Анализируя полученные результаты, отметим, что для экспериментальной группы (группа А) характерным является средний уровень социальной ответственности, что говорит об установке сотрудников ОВД на нормы и правила, склонность проявлять ответственность при наличии внешнего контроля. При этом для 
большинства испытуемых внешний контроль не всегда необходим, так как средний уровень ответственности говорит о способности к самостоятельному выполнению поручений на хорошем уровне даже при отсутствии внешнего контроля. Считаем, что испытуемые находятся в процессе формирования ответственности, и можем предположить, что данный тип ответственности находится в процессе становления (ответственность за другого, то есть социальная ответственность) формируется гораздо позже, чем ответственность за себя). Из рисунка 2 видно, что группа сравнения (контрольная группа Б) и имеет более низкие показатели социальной ответственности.

Проведение опросника «Дисциплинированность» (Д-К) (В.П. Прядеин, Н.В. Воротникова) в контрольной и экспериментальной группах позволило сформулировать следующие выводы.

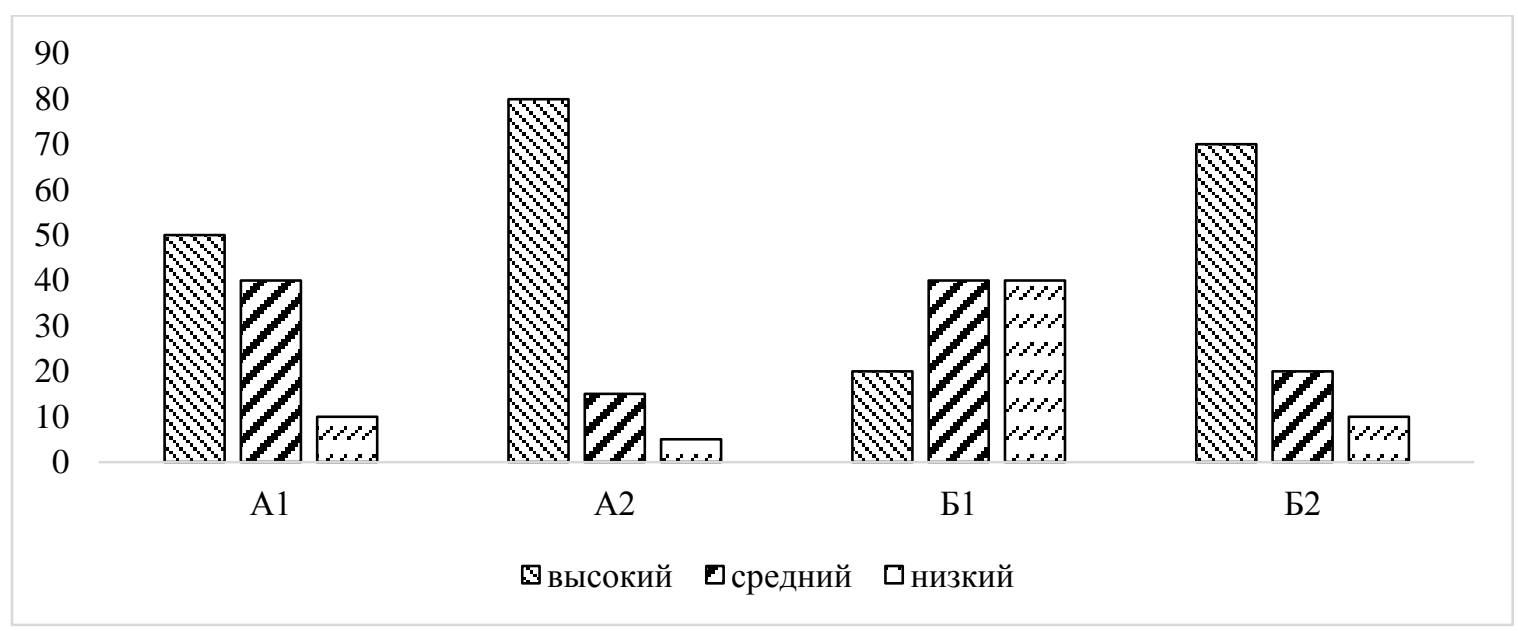

Рисунок 3. - Результаты, полученные в ходе проведения опросника «Дисциилинированность» (Д-К) (В.П. Прядеин, Н.В. Воротникова), в экспериментальныхх и контрольных группах

Так, самые высокие показатели дисциплинированности и дисциплинарной ответственности показали сотрудники ОВД со стажем работы в органах (группа А2), а также курсанты старших курсов (группа Б2), что говорит об их дисциплинированности, понимании требований субординации, принятии системы субординации, адаптации к уставным отношениям и среде образовательного учреждения. Результаты, полученные в ходе проведения диагностики социальной ответственности характеризуют сотрудников ОВД как умеренно или высоко ответственных. Как видно из рисунка 3, группа сравнения имеет более низкие показатели ответственности по проведенным методикам.

Заключение. Анализ литературы по проблеме исследования показал, что социальная ответственность личности побуждает ее к социально ориентированной деятельности с высоким уровнем самоотдачи. Такую деятельность каждый день на профессиональной основе выполняют сотрудники ОВД и данный вид профессиональной деятельности требует подлинной ответственности как самодетерминации личности. Опираясь на исследования, представленные в научной литературе, автором было выработано следующее определение социальной ответственности сотрудника ОВД: профессионально-личностная устойчивая характеристика, развивающаяся в процессе непрерывного обучения и опыта профессиональной деятельности, определяющая мотивы и формат профессионального поведения при реализации профессиональных обязанностей в соответствии с требованиями ведомственных нормативных правовых актов и пониманием последствий собственных действий как представителя профессии. Автором обоснована структура социальной ответственности сотрудника ОВД, которая включает когнитивный, этический, поведенческий, коммуникативный и рефлексивный компоненты. Опираясь на структурное строение социальной ответственности автором был подобран и апробирован комплекс диагностического инструментария для оценки уровня сформированности всех компонентов социальной ответственности сотрудников ОВД. Так, основные результаты констатирующего эксперимента по состоянию социальной ответственности у сотрудников ОВД, с различным опытом работы в системе и курсантов вуза МВД (младших и старших курсов) показали, 
что сотрудники ОВД, имеющие стаж работы в системе МВД, а также курсанты старших курсов продемонстрировали высокий уровень дисциплинарной ответственности, что может быть связано с адаптацией к условиям службы и образовательной среды юридического института с жестким внутренним распорядком дня, необходимостью ношения форменного обмундирования, требованиями субординации и др. Вместе с тем уровень социальной ответственности представителей данной выборки был диагностирован на среднем уровне. Таким образом, в ходе проведения констатирующего эксперимента была проверена валидность методик исследования и показаны принципиальные различия в представлениях дисциплинарной и социальной ответственности. Полученные результаты легли в основу программы формирующего этапа экспериментальной работы.

\section{Лumepamypa:}

1. Абульханова-Славская К.А. Типология личности и гуманистический подход / К.А. Абульханова-Славская. - М.: Наука, 1995. - 214 с.

2. Беспалова Т.М. Специфика психологической структуры ответственности военнослужащих как профессионально важного личностного свойства / Т.М. Беспалова // Вестник РУДН. Серия: Психология и педагогика. - 2012. - № 3. - С. 46-51.

3. Зубов И.В., Кузнецов В.В. Правовой аспект в формировании гражданской ответственности курсантов вузов системы МЧС России / И.В. Зубов, В.В. Кузнецов // Пожарная безопасность: проблемы и перспективы. - 2017. - № 8. - С. 73-76.

4. Коваленко В.И., Коваленко Е.В. Подготовка сотрудников полиции к реализации социальной функции в современном российском обществе: предпосылки исследования / В.И. Коваленко, Е.В. Коваленко // Проблемы правоохранительной деятельности. - 2015. - № 3. - С. 79-91.

5. Королева Е.Г. Профессиональная социализация в условиях продуктивного обучения / Е.Г. Королева // Человек и образование. - 2018. - № 1. C. 109-113.

6. Левина Е.Ю., Никулин С.Г. Социокогнитивный подход в концепции образования взрослых / Е.Ю. Левина, С.Г. Никулин // Профессиональное образование в России и за рубежом. - 2019. - № 4. - С. 106-112.

7. Литвин Д.В., Ахметов Р.С. Направления совершенствования системы специальной профессиональной подготовки сотрудников органов внутренних дел / Д.В. Литвин, Р.С. Ахметов // Физическая культура, спорт - наука и практика. - 2017. - № 4. - С. 46-54.

8. Муздыбаев К. Психология ответственности / К. Муздыбаев; под ред. В.Е. Семенова. - Л.: Наука. Ленингр. отд-ние, 1983. - 240 с.

9. Никулин С.Г. Формирование социальной ответственности в вузах системы МВД России / С.Г.
Никулин // Ученые записки Казанского юридического института МВД России. - 2020. -№ 5(2 (10)). - С. 201204.

10. Никулин С.Г. Модель формирования социальной ответственности сотрудника овд в дополнительном профессиональном образовании / С.Г. Никулин // Вестник Чувашского государственного педагогического университета им. И.Я. Яковлева. 2021. - № 2(111). - С. 189-195.

11. Пирогланов Ш.Ш. Педагогические условия формирования социальной ответственности военнослужащих: дисс. ... канд. пед. наук: 13.00.01 / Ш.Ш. Пирогланов. - Махачкала, 2017. - 145 с.

12. Прядеин В.П. Понятия ответственности исполнительности, воли как объекты психологопедагогического исследования / В.П. Прядеин // Научный диалог. - 2012. - № 1. - С. 14-19.

13. Саенко Л.А., Зритнева Е.И. Методологические подходы к изучению феномена социальной ответственности личности / Л.А. Саенко, Е.И. Зритнева // Историческая и социально-образовательная мысль. 2016. - № 5-2. - C. 141-145.

14. Терещенко А.Г., Бубнова И.С. Изучение проблемы гражданской ответственности студентов вузов как фактора становления личности будущего специалиста / А.Г. Терещенко, И.С. Бубнова // Казанский педагогический журнал. - 2017. - № 5(124). C. 120-125.

15. Чернова И.Б. Экзистенциальная проблематика философии в подготовке сотрудников полиции / И.Б. Чернова // Психология и педагогика служебной деятельности. - 2019. - № 1. - С. 89-91.

16. Яковлева О.Г. Педагогические условия развития социальной ответственности у обучающихся в вузах государственной противопожарной службы МЧС России: дисс. ... канд. пед. наук: 13.00 .08 / О.Г. Яковлева. - Санкт-Петербург, 2012. - 156 с.

\section{References:}

1. Abulkhanova-Slavskaya K.A. Typology of personality and humanistic approach / K.A. AbulkhanovaSlavskaya. - M.: Nauka, 1995. - 214 p.

2. Bespalova T.M. Specificity of the psychological structure of the responsibility of military personnel as a professionally important personal property / T.M.
Bespalova // Bulletin of RUDN. Series: Psychology and Pedagogy. - 2012. - № 3. - P. 46-51.

3. Zubov I.V., Kuznetsov V.V. The legal aspect in the formation of civic responsibility of cadets of higher educational institutions of the EMERCOM of Russia / I.V. 
Zubov, V.V. Kuznetsov // Fire safety: problems and prospects. - 2017. - № 8. - P. 73-76.

4. Kovalenko V.I., Kovalenko E.V. Training of police officers for the implementation of social functions in modern Russian society: research prerequisites / V.I. Kovalenko, E.V. Kovalenko // Problems of law enforcement. - 2015. - № 3. - P. 79-91.

5. Koroleva E.G. Professional socialization in conditions of productive learning / E.G. Koroleva // Man and Education. - 2018. - № 1. - P. 109-113.

6. Levina E.Yu., Nikulin S.G. Sociocognitive approach in the concept of adult education / E.Yu. Levin, S.G. Nikulin // Professional education in Russia and abroad. 2019. - № 4. - P. 106-112.

7. Litvin D.V., Akhmetov R.S. Directions of improving the system of special professional training of employees of internal affairs bodies / D.V. Litvin, R.S. Akhmetov // Physical culture, sport - science and practice. 2017. - № 4. - P. 46-54.

8. Muzdybaev K. Psychology of responsibility / K. Muzdybaev; ed. V.E. Semenova. - L.: Science. Leningrad. department, 1983. - $240 \mathrm{p}$.

9. Nikulin S.G. Formation of social responsibility in universities of the system of the Ministry of Internal Affairs of Russia / S.G. Nikulin // Scientific notes of the Kazan Law Institute of the Ministry of Internal Affairs of Russia. 2020. -№ 5(2 (10)). - S. 201-204.

10. Nikulin S.G. Model of the formation of social responsibility of an employee of the internal affairs department in additional professional education / S.G.
Nikulin // Bulletin of the Chuvash State Pedagogical University I. Yakovleva. - 2021. - № 2(111). - S. 189-195.

11. Piroglanov Sh.Sh. Pedagogical conditions for the formation of social responsibility of servicemen: diss. ... Cand. ped. Sciences: 13.00.01 / Sh.Sh. Piroglanov. Makhachkala, 2017. - 145 p.

12. Pryadein V.P. The concept of responsibility of performance, will as objects of psychological and pedagogical research / V.P. Pryadein // Scientific dialogue. - 2012. - № 1. - P. 14-19.

13. Saenko L.A., Zritneva E.I. Methodological approaches to the study of the phenomenon of social responsibility of the individual / L.A. Saenko, E.I. Zritneva // Historical and socio-educational thought. - 2016. - № 52. - S. 141-145.

14. Tereshchenko A.G., Bubnova I.S. Studying the problem of civil responsibility of university students as a factor in the formation of the personality of a future specialist / A.G. Tereshchenko, I.S. Bubnova // Kazan Pedagogical Journal. - 2017. - № 5(124). - S. 120-125.

15. Chernova I.B. Existential Problems of Philosophy in the Training of Police Officers / I.B. Chernov // Psychology and pedagogy of official activity. - 2019. - № 1. - P. 89-91.

16. Yakovleva O.G. Pedagogical conditions for the development of social responsibility among students in universities of the state fire service of the EMERCOM of Russia: diss. ... Cand. ped. Sciences: 13.00.08 / O.G. Yakovleva. - St. Petersburg, 2012. - 156 p.

13.00.01 - Общая педагогика, история педагогики и образования

\section{Сведения об авторе:}

Никулин Сергей Геннадьевич (г. Казань, Россия), старший преподаватель Казанского юридического института МВД России, аспирант Института педагогики, психологии и социальных проблем, e-mail: kazanreds@gmail.com

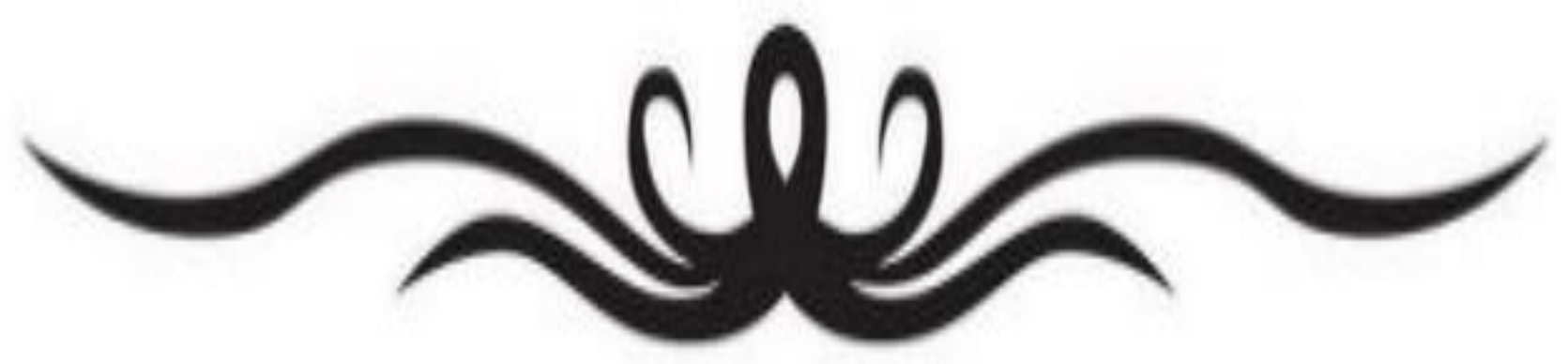

